\title{
Estudios de derecho y cine: entramados de una historia que ya se está rodando*
}

\author{
Studies of law and cinema. Threads of a story that is being shot
}

María Adelaida Galeano Pérez ${ }^{1}$

Fecha correspondencia:

Recibido: 20 de mayo de 2017.

Revisión: 29 de agosto de 2017.

Aceptado: 4 de septiembre de 2017.

Forma de citar:

Galeano, M.A. (2017). Estudios de

derecho y cine: entramados de una

historia que ya se está rodando.

Revista CES Derecho, (8), 2, 298-321.

Open access

Términos de uso

Licencia creative commons

Etica de publicaciones

Revisión por pares

Gestión por Open Journal System

DOl: http://dx.doi.org/10.21615/

cesder.8.2.5

ISSN: 2145-7719

Sobre el artículo:

* Este escrito corresponde a

un artículo de revisión de tema

derivado del trabajo de grado

titulado Derecho y cine: la

película que me quiero ver, que

comprende un estudio mucho más

amplio realizado en el pregrado

de derecho de la Universidad de

Antioquia. La investigación terminó

en octubre del año 2016.

Sobre los autores:

1. Abogada. Investigadora independiente en estudios de derecho y cine. Integrante del

\section{Resumen}

Partiendo de que el vínculo entre lo jurídico y lo cinematográfico es todavía incipiente en el contexto colombiano, no hay que desconocer que los estudios de derecho y cine son una realidad que ha tomado fuerza en otros países del mundo, demostrando una trayectoria sólida principalmente en el campo pedagógico, que se ha hecho posible gracias a la rigurosidad de los autores que lo han abordado. Conocer el estado del arte sobre la relación entre el cine y el derecho, desde el rastreo bibliográfico que se ofrece, contribuye tanto a la comprensión de su dimensión teórica como práctica, además para nuestro caso, la aproximación hacia las primigenias experiencias colombianas y las juiciosas reflexiones de algunos curiosos por el tema, constituyen los cimientos para pensarnos un lazo que tiene la oportunidad de seguirse construyendo creativamente.

Palabras clave: derecho, cine, pedagogía, sociedad, arte.

\section{Abstract}

The linkage between law and film is still incipient in the Colombian context. However, law and cinema studies actually exist and are gaining momentum in other countries, which demonstrate a solid trajectory, mainly for pedagogic purpose, based on the seriousness of the authors. Knowing the state of the art about the relationship between cinema and law makes a contribution to the comprehension of its theoretical and empirical dimension. For our case, the approach to the Colombian experiences and the reflections of some authors interested in the topic, makes the first step in a road that will be built creatively in the future.

Keywords: law, cinema, pedagogy, society, art.

\section{Introducción}

El presente artículo constituye un estado del arte que da cuenta de cómo desde el derecho se ha trabajado su relación con el cine. En otras palabras, se trata de la introducción a una narración trazada por la cámara y el papel, en la que, sin desconocer la existencia de muchos otros intelectuales y reflexiones todavía inabarcables para esta exploración, privilegio la exposición de ciertos autores hispanohablantes sobre otros, de acuerdo a ciertos criterios de selección. 
Semillero de Sociología del Derecho y Teorías Jurídicas Críticas de la Facultad de Derecho y Ciencias Políticas de la Universidad de Antioquia.
En efecto, mis búsquedas me han mostrado que los estudios de derecho y cine constituyen un fenómeno que ya cuenta con una trayectoria importante en diferentes países del mundo, aun así, pareciera conservar un aire de novedad y renovación, sobre todo en los lugares en que apenas se empieza a concebir que esto es posible, como ocurre en el caso colombiano.

En mi recorrido bibliográfico me ha surgido la impresión, a primera vista, de que estos estudios no cuentan con referentes unificados de los cuales partir para justificar o presentar la relación entre ambos campos, sin embargo apuntan en muchas ocasiones a ideas bastante similares, y tras la apariencia de que cada autor va por su lado, realmente se trazan líneas comunes que se vuelven un tanto recurrentes en la literatura de cine y derecho, a pesar de que aquellos parecen no haber conversado directamente. Es interesante percatarse también de que la demarcación de direcciones depende mucho de las concepciones que se tengan del derecho y de las experiencias personales, laborales y académicas de quienes se cultivan en el tema.

La gran mayoría de los autores que abordo al comienzo del escrito, han publicado, construido análisis o contado su experiencia desde el contexto de España, lugar en el que se ha conseguido un notable desarrollo para los estudios de derecho y cine. Del mismo modo, he encontrado excepcionalmente unos pocos estudiosos que han divulgado sus trabajos pensados desde otros sitios, como es el caso de Argentina.

Así, en la primera parte del artículo me concentro en los orígenes, los desarrollos y el aporte de los estudios de derecho y cine a la pedagogía jurídica, a partir de las elaboraciones de varios autores que no se restringen a compartir lo que ocurre en su propio ámbito geográfico, lo que me ayuda a hacer breves alusiones sobre el tema en diversos ámbitos foráneos. En la segunda parte del texto trato el tema de los estudios de derecho y cine en Colombia, con el fin de compartir los hallazgos que corresponden a mi propio contexto y partiendo de reconocer su estado naciente como una particularidad que nos caracteriza en la materia.

En este apartado me enfoco primordialmente en cuatro autores, por lo que, sin querer restarles su debida relevancia, me ocupo de forma secundaria de los demás con los que me he encontrado. Finalmente, y, en tercer lugar, desarrollo las conclusiones que albergan un breve análisis de las ideas más sobresalientes de lo previamente descrito.

Sigámosle los pasos a esta historia...

\section{Primera parte: estudios de derecho y cine fuera de Colombia}

\section{Orígenes de los estudios de derecho y cine}

Al momento de querer indagar sobre los orígenes de la relación entre el derecho y el cine fuera de Colombia, me he encontrado con la clara introducción que ofrece en varios de sus escritos el profesor Benjamín Rivaya (2010, 2006). Él explica que en la década de los noventa del pasado siglo esta relación alcanzó éxito en Estados Unidos, y de esta manera, junto con los estudios de literatura y derecho, alcanzaron un nivel de importancia en las facultades de derecho de ese país.

Tanto así que surgió el movimiento Law and Cinema o Law and Film Movement, dedicado al análisis de lo jurídico en el ámbito cinematográfico y que se encuentra ubicado en los Cultural Legal Studies, un movimiento todavía más amplio que abarca 
a la cultura jurídica y popular, de manera que este también se ocupa de otras expresiones artísticas como las historietas y las canciones.

Igualmente, explica que en el congreso de 1990 de la Law and Society Association, se abrió espacio para tratar el tema y así fue cogiendo más fuerza con el tiempo. Precisamente, por su parte, Valentín Thury Cornejo indica que en el año 1999 el presidente entrante de la misma Asociación dedicó su discurso inaugural a analizar El dulce porvenir, una película de Atom Egoyan (Sarat, 2000, como se citó en Thury, 2009, p. 59). Retomando a Rivaya, es interesante lo que cuenta sobre profesores, que sin ser todos del área de derecho sino también de historia o comunicación, trabajan el asunto en distintas universidades, ubicados incluso en Reino Unido, Escocia y Alemania; sin embargo, advierte que los estudios de derecho y cine provienen en su mayoría de Estados Unidos. Considero pertinente traer las palabras de este autor para ilustrar lo común del tema en ese lugar:

(...) Seguramente hasta hace poco era cierto que los estudios de Derecho y Cine eran una rareza curricular, pero probablemente ya estén dejando de serlo. En el caso de los Estados Unidos, tal como se estructura la enseñanza del Derecho, no sería de extrañar que Law and Film se generalizase en el tercer año, al lado de otros cursos de Law and... (Law and Society, Law and Economics, Law and Literature, Law and Psychology) ya implantados. Además, en tanto que se trataría de una transformación de la pedagogía jurídica más habitual, las corrientes críticas del pensamiento jurídico la avalarían. (Rivaya, 2010, p. 223)

Por otro lado, el profesor Rivaya $(2010,2006)$ hace claridad en que la presencia de la relación entre cine y derecho en todo el planeta no obedece en todos los casos a un proceso de difusión cultural, es decir, que no siempre ha sido objeto de exportación o importación, por lo que atribuye su éxito a la importancia que ha conseguido el cine en las sociedades contemporáneas. Justamente, afirma que el caso español surgió muchas veces impulsado por personas que no sabían siquiera de la existencia del vínculo entre derecho y cine en Estados Unidos, por lo que iniciaron sus trabajos de forma intuitiva; mientras que otros sí importaron esta experiencia de ese país para aplicarlo en el suyo.

\section{Estudios de derecho y cine en España}

En publicaciones de medios españoles es común que los autores acudan al EEES (Espacio Europeo de Educación Superior), para dar respaldo a la relación entre cine y derecho, así mismo, se llega a hacer referencia al Plan Bolonia como un factor que plantea la necesidad de reorientar la educación en derecho (Cobacho, 2012; Rivaya, 2006). Benjamín Rivaya, destacado autor en el contexto español, lo explicaba en su momento de la siguiente manera:

La transformación de la Universidad que significará la puesta en marcha del Espacio Europeo de Enseñanza Superior supone también una transformación completa de la pedagogía universitaria, incluida la del Derecho. El tradicional sistema de clases magistrales desaparece a cambio de un estudio más personalizado por parte del alumno y el correspondiente seguimiento que habrá de llevar a cabo el profesor. Entre otros objetivos, se pretende lograr una enseñanza/ aprendizaje atractiva y que desarrolle la capacidad interdisciplinaria del estudiante. Si a ello se une el dato de la necesidad del aprendizaje constante a lo largo de la vida laboral, de una formación permanente, ininterrumpida, como exige la llamada Declaración de Bolonia (1999), se observa la idoneidad de introducir nuevos recursos que faciliten el acceso al conocimiento. (...) (Rivaya, 2006, p. 21). 
Estas condiciones que le vienen a España por los retos que le toca asumir en la enseñanza superior responden a su contexto particular, por lo que se configuran en reglas de juego específicas que vienen a cumplir un papel relativamente destacado en los estudios de derecho y cine que se desenvuelven en ese país. Por ejemplo, Miguel Abel Souto (2011) en su texto "Desde la literatura, ópera, cine y televisión hasta las ciencias jurídicas y el derecho penal mediante la nueva técnica pedagógica del aprendizaje basado en problemas", parte de asumir que el EEES tiene por asiento al estudiante basándose en metodologías docentes activas, por lo que cae bien el ABP (aprendizaje basado en problemas), siendo el cine una de las fuentes apropiadas para el estudio del derecho mediante esta estrategia.

En ese orden de ideas, si el EEES es un factor que influye, tampoco se pueden desconocer esfuerzos que tienen la capacidad de sostenerse independientemente de aquel, por constituirse sobre elaboraciones conceptuales sólidas que sustentan la relación entre el cine y el derecho. Es en este punto donde destaco los trabajos de algunos autores ya abordados, y continúo por ahora con Benjamín Rivaya (2010), quien, por cierto, aparte de brindar un excelente panorama de cómo este nexo se ha extendido en el territorio español, deja demostrada una exploración juiciosa sobre aquellos autores norteamericanos que también han sabido avanzar en la materia. Cuenta que él fijaría como fecha de su implantación el año 2000, aun sabiendo de experiencias jurídico cinematográficas que se presentaron en un tiempo atrás, pero reconociéndole relevancia a esa anualidad por el espacio ganado en las universidades españolas.

En similar sentido, el mismo Rivaya (2010) afirma que el derecho no es el único que se ha involucrado con el cine, por lo que piensa que está de moda al igual que muchísimas otras áreas que también se han vinculado con él, para el caso jurídico enuncia elementos concretos en los que observa el fenómeno en España: la fundación de asignaturas sobre derecho y cine en las facultades de derecho, los cursos de extensión universitaria, otros cursos universitarios y cursos de formación permanente del Consejo General del Poder Judicial, además, la aparición de diversas publicaciones, proyectos de investigación y páginas web que se ocupan del asunto, reconociendo que existen portales virtuales, incluso de otros lugares, como Perú o Norteamérica. Una fuente que destaco entre las que menciona este profesor es la colección Cine y Derecho de la editorial española Tirant lo Blanch, dirigida por Javier de Lucas, que cuenta con numerosos textos enfocados en múltiples cuestiones que hacen parte de los estudios de derecho y cine.

Siguiendo las ideas de este autor, en cuanto a que el caso español no es tanto una consecuencia de difusión cultural por importación de la experiencia de Estados Unidos, no obsta para que se pueda identificar en ciertos textos suyos la asociación y el gran conocimiento que tiene de los estudios de estos autores extranjeros. Entre los escritos que he abordado, encuentro especialmente sobresaliente el titulado "Derecho y cine todo lo que siempre quiso saber sobre el derecho y nunca se atrevió a preguntar", debido a las vastas referencias que hace sobre ellos. Partiendo de estos hechos, entiendo que la construcción de sus reflexiones acerca de cine y derecho, si bien surgieron por ese deseo intuitivo, también han venido siendo alimentadas por los trabajos de académicos que no sólo están en su mismo país sino por otros muchos que se constituyen a partir de las vivencias en otras naciones. 
Aportes teóricos de Benjamín Rivaya en torno a los estudios de derecho y cine

Partiendo del recorrido de Benjamín Rivaya en los estudios de derecho y cine, resulta de gran valor tomar sus consideraciones sustanciales frente al tema. Para empezar, él reconoce que fue muy cerca a la filosofía del derecho y a la historia del derecho que nació el vínculo entre cine y derecho, en tanto, por ejemplo, dicha filosofía se ha ocupado de relacionar lo jurídico con otros fenómenos y saberes (Rivaya, 2010). De otro lado, señala que los estudios de derecho y cine se pueden reconducir a la sociología del derecho, pudiéndose conformar otra rama de esta, según él, la sociología de "el Derecho en el cine" que además incluiría la televisión (Rivaya, 2005-2006), y hasta advierte que a lo mejor no sea adecuado nombrar con el rótulo de "Derecho y Cine" todos los lazos que pueden originarse entre ambos, y se deba mejor circunscribir a los estudios humanísticos que analizan el fenómeno jurídico en la narración cinematográfica (Rivaya, 2006).

Por otro lado, no se puede negar la rigurosa exploración emprendida por este autor en cuanto a la riqueza de sentidos que alberga esta relación, por lo que voy a exponer a grandes rasgos en qué consisten. En primer lugar, es interesante su cuestionamiento acerca de si existe o no el género del "cine jurídico", respecto a lo cual expresa que esto es algo que se define por convención y que hasta el momento no hay una que lo haya creado. Sin embargo, indica que, de tomarlo por existente, es un género temático, es decir, que se define por exponer asuntos jurídicos que no se restringen en los dramas judiciales ni en la trama criminal, se solapa con otros géneros y es la intensidad del dato del fenómeno jurídico lo que resuelve su pertenencia a él. Desde un criterio restringido no podría hablarse de la existencia de tal, no obstante, por lo menos permite admitir que el cine utiliza argumentos jurídicos y se aparece en casi todos los géneros (Rivaya, 2010). Fuera como fuera, desde su punto de vista, hay géneros que por principio son jurídicos: el cine negro, el cine western y el cine político (Rivaya, 2005-2006).

En segundo lugar, es atractiva su consideración acerca de que es posible agrupar los argumentos jurídicos en el cine según la clasificación de los sectores del derecho. Esto consiste en identificar unos mismos rasgos en distintos filmes que les permite asociarse con las ramas del derecho. Así, por ejemplo, explica que el derecho procesal se vincula con películas de juicios y de jurado, el derecho constitucional con obras que tienen que ver con procesos revolucionarios o golpes de Estado, e igualmente pasa con otras áreas jurídicas como son la penal, la laboral, la de los derechos humanos, entre otros (Rivaya, 2005-2006). A propósito de esto, no sobra decir que cuenta con análisis muy interesantes en los que trabaja lo que para él es el capítulo fundamental de la relación entre el derecho y el cine: el cine de los derechos humanos (Rivaya, s.f.).

En tercer lugar, no puedo dejar de lado otras apreciaciones que él comparte y que por supuesto considero fundamentales. Rivaya se refiere a dos grandes teorías del cine, esto es, el cine entendido como arte y el cine asumido como fenómeno de propaganda y control social. Éste último es el que me resulta más interesante porque contempla el papel que juega el cine en la orientación de ideas y prácticas, preguntándose también por el poder del público para controlar la industria cinematográfica, dando lugar finalmente a considerar el cine como un instrumento de crítica social (Rivaya, 2005-2006). Considero muy ajustadas las palabras del profesor al respecto: "Realmente resulta difícil creer que el cine, un medio de comunicación de 
masas, no produce o, al menos, no puede producir un efecto de control social, por más que sea demasiado complejo, quizás imposible, medirlo empíricamente y con exactitud. (...)" (p. 148)

En cuarto lugar, debo destacar del autor el sentido que encuentra a la relación entre derecho y cine. Por una parte, él es consciente de las relaciones que existen entre el cine y la sociedad, citando a varios autores, entiende que el cine refleja el derecho y las creencias populares que sobre él existen (McDowell, 2000, p. 73; Sarat, 2000, p. 9; Bergman, 2001, p.1410, como se citó en Rivaya, 2005-2006, p. 149), e igualmente, piensa que este participa de la conformación de las creencias sobre la realidad jurídica (Rivaya, 20052006). Es aquí donde encuentra pertinente la participación de la sociología del derecho y reconoce que, aunque las investigaciones en la materia no son necesarias, y más bien lujosas, tienen sentido tanto en la investigación como en la formación jurídica (Rivaya, 2005-2006; 2010). Me parece conveniente traer la siguiente cita de Rivaya García que evidencia un poco la idea:

(...) Desde luego, la formación de un jurista pudiera quedarse en el aprendizaje de leyes y artículos de códigos, pero pronto se evidenciaría que semejante retención de datos resulta escasa. Ese jurista sería como un historiador que sólo se ocupa de memorizar noticias históricas. Sabemos, sin embargo, que tanto el historiador como el jurista han de ser capaces de conectar unos fenómenos con otros, de tal forma que el objeto de estudio se convierta en legible. Así, conectar dos fenómenos en principio tan ajenos resulta por lo menos una actividad interesante y formativa. (...) (Rivaya, 2010, p. 227)

Finalmente, me parece adecuado aclarar que el profesor Benjamín Rivaya utiliza la nominación "Derecho y Cine" con una intención particular, pues guarda una diferencia con decir "cine y derecho", ya que él, junto al resto del grupo de la Universidad de Oviedo, identifican el cine como el objeto y el factor jurídico como el punto de vista, pues le prestan atención al dato objetivo de aparición del derecho tanto como al dato subjetivo de la perspectiva. Aunque, este autor admite que existen otras posturas también legítimas (Rivaya, 2010).

\section{Derecho y cine en la pedagogía jurídica}

Las reflexiones de las que da cuenta la literatura en derecho y cine tienen una concentración especial en la educación en derecho, referidas en la mayoría de los casos a cursos de educación superior dirigidos a estudiantes de derecho, las cuales terminan por erigir al aula universitaria en el sitio primordial para la socialización y la formación desde la experiencia jurídico-cinematográfica. Partiendo de esta consideración, ahora me extiendo al estudio de cuatro autores más que desarrollan sus posturas con admirable profundidad, sea que tiendan a ocuparse de un eje teórico o de un eje práctico, respecto a la introducción del cine como recurso didáctico en la enseñanza del derecho.

Algo que queda muy claro en las propuestas y reflexiones de los autores cuando tratan el tema en la pedagogía jurídica es que el cine se asume de manera seria, en contraposición a que sea un pasatiempo sin provecho académico alguno, apuntando también a que sea un instrumento didáctico. Desde ahí se delinean posturas de diferentes tonos críticos, o que muchas veces sin ser necesariamente críticos, se vierten y alimentan el escenario que les subyace, el cual es el educativo.

La elección de estos autores la he basado en los siguientes criterios: (i) sus trabajos se ubican en el contexto español y argentino; (ii) sus reflexiones en torno al tema, 
a mi juicio, gozan de una admirable profundidad y calidad teórica o de un riguroso análisis de lo práctico; (iii) las lecturas que sobre ellos he hecho se encuentran entre la bibliografía a la cual he podido acceder y (iv) son autores que he podido abordar dentro del tiempo que he dedicado al estudio bibliográfico. Para empezar, abordo a tres autores que desarrollan con especial fortaleza el eje teórico, razón por la que observo apenas pistas de lo práctico en ellos.

José Luis Pérez Triviño, por ejemplo, autor del texto "Cine y Derecho. Aplicaciones docentes", de la Universidad Pompeu Fabra, de Barcelona, es uno de los individuos que comparte con su escrito planteamientos sobresalientes y de gran dedicación, que son muestra del pensamiento crítico en esa vía. En su artículo, Pérez Triviño maneja una concepción de la docencia jurídica que acepta las normas en relación con el impacto que tienen en la vida de las personas y con un contexto, en contraposición a su mera comprensión abstracta, así mismo cuenta que la visión formalista del derecho está en crisis y que este cambio ha traído nuevas formas de acercamiento y áreas de estudio, abriéndose un paso apropiado a su relación con el cine. Dice que:

(...) Los juristas no deberían ser meros autómatas en la comprensión y aplicación de las normas jurídicas. Éstas, como he señalado antes, se incardinan en un contexto social, político y moral, y su aplicación a los casos concretos tiene importantes repercusiones en la vida de los individuos. (...) (Pérez, 2007, p. 72).

Por otro lado, al preguntarse por cómo debería ser la docencia del fenómeno jurídico, le apunta tanto a un perfil ideal de jurista, como al proceso educativo que viven los estudiantes, al estar acompañados por la guía del profesor que encuentra una oportunidad de análisis en las películas. En relación con esto, al enunciar las posibilidades existentes con el cine, afirma que:

(...) Sin duda, el alumno a través de este método llevará a cabo un acercamiento al estudio jurídico que es simultáneamente más realista, más interesante y más amable. Y en definitiva, estará más motivado para analizar una cuestión que, quizá explicada teóricamente en el aula, le habría motivado insuficientemente al no captar su contexto, su relevancia o sus diversas consecuencias prácticas. (Pérez, 2007, p. 72)

Su comprensión del derecho en relación con diversos aspectos sociales y su consideración de que el estudio a través del cine se torna relevante en el contexto de crisis de la visión formalista, respalda la atribución de la "potencialidad contextual" que le confiere al cine, la cual consiste en la perspectiva amplia y compleja que es capaz de mostrar sobre el derecho. De la misma forma, afirma que el factor emocional en la enseñanza genera interés y comprensión, por lo que le atribuye igualmente una "potencialidad emocional" al cine que consiste en su aporte a la formación interdisciplinar y a la consideración de aspectos prácticos y emocionales. En este punto aporta una pista práctica, ya que alerta sobre la responsabilidad que tiene el docente en la selección de las películas y la explicación que este haga, debido a que ve un riesgo en esta potencialidad, en tanto traería una inadecuada comprensión de lo jurídico o los estudiantes percibirían emociones que no se justifican fácilmente desde la moral o la política.

Así, toma al cine como un transmisor de pautas que permite adoptar actitudes o valores, mediante la oportunidad que se tiene de ponerse en el lugar del otro, lo cual encaja también en su preocupación por una formación que comprenda teoría, 
actitudes y capacidades. Siendo coherente con sus reflexiones, se refiere a los juristas, e incluso a los jueces, para explicarse: "En este sentido, una buena sentencia es aquella en la que el juez puede tomar en consideración todo el conjunto de factores que intervienen en el momento de su aplicación, factores que, por otro lado, no se enseñan con una formación estrictamente dogmática." (Pérez 2007, p. 73)

Finalmente, es pertinente enunciar que otra de las pistas prácticas que él propone consiste en que los estudiantes vean colectivamente las películas y la discutan juntos con la guía del profesor, lo cual se asemejaría bastante a un ejercicio de argumentación jurídica. Además, distingue dos maneras de enfocar el papel del cine en la enseñanza del derecho. Una se trata de las representaciones del derecho en el cine, lo que él denomina "el derecho en el cine", la otra, se refiere al análisis del fenómeno jurídico cuando adopta herramientas de la representación o crítica cinematográfica, y es lo que él llama "el derecho como cine". Para él, en la docencia jurídica debe primar la primera visión, ya que se debe distinguir el método del objeto.

Valentín Thury Cornejo es el siguiente autor que quiero tratar. En el texto suyo que he abordado, titulado "El cine, ¿nos aporta algo diferente para la enseñanza del Derecho?", se identifica como profesor de la Universidad Católica Argentina e investigador adjunto del Consejo Nacional de Investigaciones Científicas y Técnicas de Argentina. Su juiciosa construcción crítica destaca especialmente porque se convierte en una propuesta con un esfuerzo teórico intencional en la preocupación manifiesta de darle bases constructivas a la relación entre cine y derecho, e indicativa de que existen mayores potenciales en este vínculo; lo cual lo distingue de los demás autores que he estudiado, y en su mayoría arraigados al contexto español.

Muy en concordancia con lo que explica Rivaya García, cuenta que la utilización del cine en el entorno pedagógico es una práctica común que inició en el ámbito anglosajón hace más de un par de décadas. Según él, esto se debió a que el derecho se abrió a otras disciplinas, a una explosión de estudios culturales y de áreas que tienen a los medios de comunicación como objeto, y, citando a Guy Osborn, a que se buscaban otros recursos en la enseñanza (2001, como se citó en Thury, 2009, p. 59). Su postura es muy interesante, pues dice que su experiencia docente le permitió darse cuenta cómo en su entorno inmediato el cine terminó por convertirse en un instrumento más del derecho que no aportaba elementos nuevos, quedando como mero ejemplo.

La preocupación de Thury Cornejo reside entonces en la colonización que hace el derecho sobre el cine, producto de una carencia teórica, aunque tiene en cuenta a la autora Orit Kamir para afirmar que recientemente se comenzó a teorizar sobre Law and Film (Kamir, 2005, como se citó en Thury, 2009, p. 60), y es así como se propuso construir una base de sustentación para la relación entre derecho y cine, bajo la cual encuentra respuestas satisfactorias sobre la riqueza que guarda el cine en la enseñanza. Sus palabras parecen contundentes:

(...) En este sentido, el contenido -caso jurídico- prima sobre la forma -cinematográfica- y el derecho coloniza un nuevo instrumento. En la superficie adoptamos un enfoque interdisciplinario pero en lo profundo, ese cruce de conocimientos no cuestiona ni aporta elementos nuevos sino que suele quedar en el papel de mero ejemplo o ilustración. (...) Sospechamos en el cine una potencialidad mayor que la de ser una mera exposición de un caso jurídico, pero carecemos de una base profunda en la que apoyar esas intuiciones y sistematizarlas, dotando así a este ejercicio de mayor eficacia pedagógica. (...) (Thury, 2009, p. 60) 
Este autor señala cuatro aportes fundamentales que hace el cine a la enseñanza del derecho. El primero de ellos es la contextualización que hace el cine, es decir, pone al derecho en su contexto en tanto logra relacionarlo con la vida. El cine logra conectarse con relaciones humanas y sociales, muestra los mitos que fundan al ordenamiento jurídico moderno, y apoyándose en Walter Fisher, explica que trasciende la racionalidad cartesiana y supera los dualismos tradicionales (1989, como se citó en Thury, 2009, p. 64). En otras palabras, supera esa legitimidad que logra sobre sí mismo y la consecuente reproducción que siguen los operadores jurídicos. Al igual que Pérez Triviño, Thury Cornejo ubica al cine entre los enfoques alternativos que conectan al derecho con la realidad social.

El segundo aporte al que se refiere es el involucramiento emocional que se produce al ver una narrativa cinematográfica, ya que hay una cierta desprevención racional, y tomando a Currie, da por supuesto que el espectador acepta jugar el juego de la representación (2004, como se citó en Thury, 2009, p.67). El tercer aporte tiene que ver con el ejercicio hermenéutico, pues basándose en Gadamer y Brummett respectivamente, enuncia que la interpretación fílmica se contrapone a los métodos interpretativos científicos (Gadamer, 1988, como se citó en Thury, 2009, p. 71), asumiendo que hay una actividad de homología entre la película y la realidad (Brummett, 2004, como se citó en Thury, 2009, p. 69), lo cual, al implicar un acto hermenéutico, deja entender al actor jurídico como un ser subjetivo.

El cuarto aporte del que habla subyace en la relación entre el derecho y la cultura popular. Basándose en otros autores, dice que el cine crea representaciones sociales (Zillman \& Bryant, 2002, como se citó en Thury, 2009, p. 73), por lo que para él esto condiciona la visión sobre realidades jurídicas, y así, tanto cine como cultura popular reproducen estereotipos. Tomando también una cita de Sherwin, dice que el derecho y la cultura popular se comunican, crean relaciones y se forman entre sí (2004, como se citó en Thury, 2009, p. 73). Al tomar así las cosas, llama la atención sobre la oportunidad de autorreflexión desde el derecho y en el espacio educativo, e indica que el derecho y el cine son formaciones culturales que construyen conceptos y se inciden mutuamente (Kamir, 2005, como se citó en Thury, 2009, p. 75). A raíz de ello, Thury Cornejo termina advirtiendo otra dimensión del cine, y es que se constituye en un formador del derecho.

Entre sus pistas prácticas, este autor tiene una propuesta de organizar la currícula teniendo en cuenta que el curso que relacione el derecho con el cine debe mezclarse con los métodos tradicionales, se inclina por las obras cinematográficas donde lo jurídico aparece a un nivel general y simbólico en preferencia a las películas que son "expresamente" jurídicas, es decir, con abogados o un proceso judicial, y recomienda combinar películas nacionales y extranjeras. Adicionalmente, cree conveniente que se cuente con el apoyo de un material secundario, como podrían ser las lecturas de estudios críticos sobre las películas, que se preparen guías para conducir al estudiante, y finalmente, que los discentes vean las películas por su cuenta para que sean discutidas luego en clase y evitar así que deban procesarlas en unos pocos minutos.

Paso ahora a la última postura crítica que me interesa destacar, correspondiente otra vez a Benjamín Rivaya, quien en su texto llamado "Derecho y cine. Sobre las posibilidades del cine como instrumento para la didáctica jurídica", se pregunta por la posibilidad para que el cine aporte algo atractivo y nuevo a dicha didáctica. Él reconoce que el tradicionalismo de la pedagogía jurídica española ha sido duramente criticado, a causa de la actitud pasiva que se fomenta en los estudiantes y la relación 
mecánica que se establece con ellos en manos de la clase magistral, sin embargo, rescata que no todas estas clases son malas en tanto sepan estimular, y lo que no comparte, es que se constituyan en el único procedimiento pedagógico utilizado en la educación, a su juicio, se requieren otros medios para dicha didáctica.

En ese sentido, este autor considera que el cine está llamado a jugar un papel en la transformación educativa provocada por el EEES en España y halla en él múltiples cualidades para ese contexto: atractiva innovación educativa, aporte a la mejora del aprendizaje del alumnado, mejora en la calidad de la enseñanza, potencia la interdisciplinariedad y ayuda a la formación permanente. Además, anota que no por ello el cine debe sustituir los métodos tradicionales de enseñanza, es decir, que la pedagogía jurídica debe seguir siendo literaria, o sea, que debe concentrarse en las habilidades de lectura, escritura, escucha y expresión oral.

En otros de sus escritos, deja ver también que sus intereses están encaminados a que el jurista rompa la visión compartimentada de la realidad y conecte unos fenómenos con otros, en la búsqueda de una educación holística, para lo cual no bastarían los tratados y leyes (Rivaya, 2010; 2005-2006). No puedo dejar de lado algo llamativo que él menciona, y es que junto al "derecho en los libros" y al "derecho en acción" está un "derecho en imágenes", el cual participa con potencia en la conformación de la mentalidad jurídica popular, del imaginario jurídico, que contribuye igualmente a construir ese mundo del derecho (Rivaya, 2010; Sarat, 2000, p. 6-7, Martínez, 1992, p. 17-38, Sherwin, 2001, p. 1519-1543, como se citaron en Rivaya, 2005-2006, p. 149).

Para terminar, sus claves prácticas lo llevan a contemplar dos modalidades en que se puede introducir el cine en la enseñanza del derecho. Una de ellas es actuar como apoyo para un tema concreto en una asignatura convencional, y la otra, consiste en ser parte esencial de una asignatura de "Derecho y Cine" que sea de carácter introductorio o especializada en una institución concreta. Las sesiones estarían estructuradas como un cine-fórum, que incluyan preferiblemente una preparación previa de los estudiantes y un análisis teórico posterior a la proyección; sabiendo que se podría poner en marcha o la "tesis de la disculpa", que utilizaría el filme de excusa para desarrollar luego una explicación jurídica, o la "tesis del comentario jurídico del texto fílmico", la cual toma el dato cinematográfico como su objeto de estudio y lo interpreta desde la perspectiva jurídica.

Continúo ahora con los autores que trabajan con mayor profundidad el eje de lo práctico, lo que por supuesto brinda aportes importantes para la puesta en marcha de una experiencia jurídico-cinematográfica en el ámbito educativo. En cuanto a Yolanda Cano Galán (s.f.), quien se identifica en un escrito como profesora de la Universidad Rey Juan Carlos, institución educativa española, ella fundamenta la relación entre el cine y el derecho en la necesidad de superar las clases magistrales y en una nueva estrategia en el marco del EEES, y comparte la experiencia de la Facultad de Ciencias Jurídicas y Sociales de la misma Universidad, en la que se ha hecho un esfuerzo por implementar una metodología de enseñanza que vincula el cine.

En su propuesta, la autora concibe que las metodologías didácticas aplicadas a la docencia en ciencias jurídicas requieren de un diseño estratégico, por lo que presenta una propuesta muy exigente, pormenorizada y rigurosa mediante pautas que deben seguirse para una adecuada utilización del cine en el aula, que según ella, se debe componer de una planificación docente, así como del trabajo del estudiante y del profesor, todo esto para ser realizado en fases que comprenden el momento 
previo a la proyección, la proyección misma y la post-proyección. Para la fase previa brinda algunas pautas: selección de película, determinación de objetivos, preparación del trabajo que sería desarrollado por el estudiante y selección del momento de proyección.

En la fase de proyección enuncia la realización de un repaso previo del temario, que tiene que ver con el contenido de la película, y si es el caso, la entrega y análisis de la guía de la actividad. Para la última fase menciona la realización de un debate guiado, y opcionalmente, de un trabajo del estudiante, la respectiva evaluación de esta y la evaluación que brindaría el discente a la actividad. En cuanto a la experiencia en la Universidad, explica que la metodología fue aplicada para la asignatura de Derecho del Trabajo, en la Licenciatura en Administración y Dirección de Empresas, fruto del proyecto "Metodología del autoaprendizaje en materias jurídico laborales", dirigido por el profesor Antonio V. Sempere Navarro.

Yolanda Cano trata analíticamente el desarrollo del trabajo del profesor y la evaluación de la actividad, donde detecta aspectos que pueden modificarse, como lo es la manera de proceder para calificar. En general, valora positivamente la propuesta al considerarla válida para la adquisición de competencias y reconoce que los cuestionarios contienen también estimaciones positivas y negativas por parte de los estudiantes. Ella dice que:

Se ha potenciado la creación de un pensamiento crítico sobre los aspectos aprehendidos en el transcurso del proceso de aprendizaje de los contenidos de la asignatura, especialmente en relación con dos aspectos: importancia de la toma de decisiones en el ámbito laboral y compromiso ético con el trabajo. (Cano, s.f., sección V, párr. 21)

Finalmente, un aspecto que resulta interesante es que esta autora contempla la posibilidad de que a los cursos asistan estudiantes con necesidades especiales, algo totalmente novedoso y único en la bibliografía que he podido examinar:

Es posible que el aula no disponga de medios adecuados para la utilización de esta técnica de enseñanza, bien porque no esté insonorizada y se moleste el trabajo de otros profesores y estudiantes en aulas cercanas, bien porque no se dispone de medios de proyección, bien porque existen estudiantes con necesidades especiales (invidentes o con problemas auditivos, por ejemplo), etc., en estos supuestos, será necesaria la coordinación del profesor con el personal de la universidad para habilitar un espacio adecuado para el desarrollo de la actividad. (Cano, s.f., sección III, párr. 16)

Ahora, pasando a Octavio Salazar Benítez (2015), me baso en su texto nombrado "La enseñanza del Derecho Constitucional a través del cine", en el que establece el nexo entre cine y derecho directamente con el derecho constitucional, el cual asume como el derecho más "político", al tiempo que considera que toda película es política. Parte de reconocer que tanto el derecho como el cine se ocupan de la vida y toma a este último como una herramienta pedagógica idónea con la que él procura transmitir valores constitucionales y ética, y que guarda conexiones entre su ficción y la ficción del ordenamiento jurídico. Él destaca la idea de que el cine sabe reflejar la democracia y que está rodeado de factores, como son el emocional, la racionalidad, la crítica, las actitudes y los valores, superando el binomio razón-emoción y dando lugar a la empatía, es decir, al reconocimiento en el otro. 
El autor se basa en la experiencia del profesorado del área de derecho constitucional del Departamento de Derecho Público y Económico, que conforma el Grupo Docente 130 de la Universidad de Córdoba, en España, el cual se ha ocupado de canalizar la pretensión de enseñar a través del cine. Así, comparte su recorrido por medio de múltiples experiencias: cursos de extensión universitaria, las jornadas "La igualdad en rodaje. La construcción del género en el reciente cine español", el proyecto de innovación educativa "I Plan de Innovación Educativa de la Universidad de Córdoba", tres proyecciones realizadas en la Filmoteca de Andalucía dirigidas a estudiantes de un curso y al público general y el Proyecto Coordinado de Innovación Educativa "Cine, derecho e imágenes: los reflejos de la dignidad". Este último trajo otros proyectos: ciclo en Filmoteca de Andalucía, certamen fotográfico y la apertura de una página web llamada Derecho al cine' ${ }^{1}$.

Sobre las tres proyecciones llevadas a cabo explica las fases que se siguieron: selección de películas; exploración de las posibilidades didácticas de la película junto con la preparación de materiales; las sesiones que comprende la presentación de la película, la proyección y el debate; la posterior reflexión en el aula y la reflexión crítica individual. Igualmente hay que destacar que la igualdad de género fue instaurada como un eje transversal a todos estos proyectos, en los que se busca que los docentes sean provocativos y los estudiantes cuestionadores.

Octavio Salazar afirma que el uso del cine en la enseñanza permite desarrollar competencias y habilidades que no se dan fácil con el empleo de los métodos tradicionales, expresa la necesidad de que los docentes se acerquen a los lenguajes de la cultura de la imagen, propios de las jóvenes generaciones, y rescata lo positivo que resulta el compartir el cine en un espacio colectivo si se le compara con el hacerlo de manera individual. Por otra parte, como lo demuestra el autor con aquel sitio web, hay que advertir que las experiencias prácticas educativas no están condenadas a parar en el aula, la conformación de redes y la fundación de portales virtuales no son una añadidura efímera de estas preocupaciones didácticas, de hecho, desde mi punto de vista, le han otorgado mayor vigor a la relación entre derecho y cine.

En el caso de Derecho al cine, esta manifiesta en su sección principal la intención de reflexionar y debatir acerca de los derechos humanos mediante el séptimo arte, con el objetivo de que los estudiantes se involucren activamente con su ética (Derecho al cine. La Ciudadanía en Rodaje, s.f.); Salazar Benítez expone también los apartados con los que cuenta, los cuales permiten enterarse de las actividades que trae el proyecto, contienen publicaciones de noticias relacionadas con eventos cinematográficos o películas, documentos, trae una lista de enlaces, un cinefórum y fichas de trabajo sobre temas de derecho constitucional. Aparte de este sitio virtual, conozco otro caso español muy interesante llamado Proyecto DeCine, al cual corresponde la publicación de Ángel Cobacho López, a quien ya cité varias páginas atrás. ${ }^{2}$

Proyecto DeCine, como se indica en su página, es una revista electrónica de la Red de Profesores para la Elaboración de Materiales Didácticos para la Enseñanza del Derecho a través del Cine, fruto de un proyecto que tuvo sus iniciativas en la Facultad de Derecho de la Universidade da Coruña en el año 2005, consistentes en cine-forums, la utilización de películas como recurso didáctico en el ejercicio docente, la creación de un espacio sobre la materia en la biblioteca y la de una asignatura llamada Apro-

1. La dirección de Derecho al cine es la siguiente: http://www.uco.es/derechoalcine/

2. La dirección de Proyecto DeCine es la siguiente: https://proyectodecine.wordpress.com/ 
ximación cinematográfica al Derecho, todo lo cual se concretó por fin en esta revista periódica, herramienta fundamental para la Red que busca la innovación docente y que en realidad trasciende a la publicación misma por los efectos que puede traer en el espacio universitario nacional.

Justamente lo que más me llama la atención de la Red, es que se propone establecer una red de docentes de universidades españolas para intercambiar experiencias y materiales didácticos que tienen que ver con el uso del cine en la enseñanza del derecho, publicarlos y colaborarse entre sí. Se trata de trabajar conjuntamente para enriquecerse con apoyo en su portal virtual, en el que tienen consignado mucho material, especialmente fichas didácticas que siguen un modelo común. Así, si de asuntos virtuales se trata, pienso que es conveniente contemplar otros sitios, que, aunque no están pensados quizás para la educación en derecho, podrían perfilarse como instrumentos que se podrían tener en cuenta por lo menos para proponer un tema de debate. Ejemplos de estos son las webs peruanas Enfoque Derecho y Cine \& Derecho $^{3}$.

Enfoque Derecho es un portal web de actualidad jurídica que pertenece a la Asociación Civil THĒMIS (Thēmis, s.f., sección Acerca de Thēmis), la cual realiza seminarios, cursos y maneja otras publicaciones, y es dirigida por estudiantes de la Facultad de Derecho de la Pontificia Universidad Católica del Perú. Tal y como se puede observar en la página, en ella aparecen publicaciones que relacionan el arte con el derecho, en las cuales están contenidas las vinculadas con el cine, además cuenta con "Histeria Cinéfila", según lo explica, una saga de videos en los que diferentes abogados comentan aspectos jurídicos de películas significativas. Por su parte, Cine \& Derecho se identifica como un blog de derecho, escrito por juristas que interpretan sus imágenes en el cine y que se sienten atraídos por las escenas de lo judicial que allí aparecen. Igualmente cabrían en este listado otras fuentes virtuales, como pueden ser la sección de cine y derechos humanos de Amnistía Internacional de Cataluña y el blog Películas de abogados 4 .

\section{Segunda parte: estudios de derecho y cine en Colombia}

\section{Introducción}

En mi trayecto personal como estudiante de derecho el cine tuvo una escasa presencia, aunque algunos profesores insertaban la experiencia fílmica en las clases, siendo más común que esta apareciera en grupos de estudio extracurriculares o cursos optativos, no llegó a representar una opción lo suficientemente fuerte en mi plan de estudios, y en efecto, eran las lecciones magistrales las que reinaban en las metodologías de enseñanza. Al igual que el caso español, siento que la percepción que fácilmente nos podemos generar los estudiosos del derecho en Colombia, es que el formalismo jurídico ha trazado con contundencia un ambiente árido en las aulas de las facultades en las que se enseña, y que una manera distinta para abordarlo, merece una transición y una apertura a otras mentalidades que permita ampliar la propia y construir nuevos puentes con la sociedad, y por qué no, con otras realidades posibles.

A partir de mis exploraciones, me he dado cuenta de que en Colombia los estudios de derecho y cine conforman una experiencia que apenas empieza a emerger, por lo que todavía es muy novedosa en nuestro medio. Son pocas las personas que se han

3. Las direcciones de Enfoque Derecho y Cine \& Derecho son las siguientes: http://enfoquederecho.com/ y https://cineyderecho.wordpress.com/ 4. Las direcciones de Amnistía Internacional de Cataluña y Películas de abogados son: http://www.amnistiacatalunya.org/edu/pelis/y http://peliculasdeabogados. blogspot.com/ 
aventurado a realizar trabajos profundos y reflexiones sobre este tema y que han contribuido a fortalecerlos incluso mediante la puesta en marcha de proyectos. En este apartado, los autores sobre los que me concentraré con mayor dedicación los he elegido bajo los siguientes criterios: (i) se ubican en el contexto colombiano, (ii) se encuentran contenidos en la recopilación del material bibliográfico al cual he podido acceder, (iii) los he abordado en el tiempo que he dedicado al estudio de este material y (iv) sus reflexiones son fundamentadas con rigor y/o tienen aportes valiosos en cuanto a lo práctico.

Con esta selección no ignoro los trabajos de otros académicos como son los profesores de la Universidad Autónoma Latinoamericana, en la ciudad de Medellín. Ellos son Martín Agudelo Ramírez, quien ha escrito sobre el tema y recientemente ha publicado un par de libros llamados "Cine y Derechos Humanos. Una aventura fílmica" y "Cine y conflicto armado en Colombia", de los años 2015 y 2016 respectivamente; y José Fernando Saldarriaga Montoya, quien en sus elaboraciones advierte la relación del cine con la ciencia política, una mirada que se debería integrar sin dudas al derecho, contando entre sus publicaciones un texto titulado "Ciencia política y cine. Un modelo para armar".

Tampoco podría dejar de lado dos portales virtuales que conozco y que guardan relación con las reflexiones de cine y derecho. Son ellos los dirigidos por el abogado Andrés Molina Ochoa, con su blog El derecho del cine, que, aunque inactivo, contiene todavía los escritos publicados entre los años 2011 y 2014, y la página web personal de Andrés Botero Bernal, licenciado en filosofía y letras, abogado y profesor de la Universidad Industrial de Santander, con su destacada sección Recomendaciones de cine. Así también, debo enunciar la apuesta práctica del Semillero de Relaciones entre el cine, el derecho y el análisis de conflictos, liderado por el profesor Juan Camilo Mejía Walker en la Facultad de Derecho y Ciencias Políticas de la Universidad de Antioquia. Finalmente, puede suceder, aunque con gran escasez, el toparse con la existencia de artículos de revista o tesis realizadas por estudiantes de derecho y que tienen que ver directamente con el tema, lo cual da la idea de que es algo que realmente se está desenvolviendo y empezando a ganar un espacio. ${ }^{5}$

Precisamente uno de los cuatro autores en los que concentro mi atención es Carlos Jerónimo Atehortúa Arteaga, quien, en su época de estudiante de derecho de la Universidad Externado de Colombia, elaboró su tesis sobre la relación entre el derecho y el cine. Paralelamente, abordo con más detenimiento a los docentes César Oliveros Aya, Luis Alfonso Fajardo Sánchez y Adriana María Ruíz Gutiérrez. En un primer momento me dedicaré a exponer de manera separada, y debido a sus peculiaridades, las principales ideas de Atehortúa Arteaga, y luego de manera conjunta, a Oliveros Aya y Ruíz Gutiérrez, quienes comparten la virtud de constituir diversos fundamentos que aportan a la reflexión teórica, el uno con un enfoque amplio, y los otros dos, centrados en la pedagogía jurídica. A continuación, pasaré a exponer a Fajardo Sánchez y retomaré nuevamente a Adriana María Ruíz y a César Oliveros, por sus interesantes aportes para lo práctico o por sus experiencias ya vividas en torno al tema. Para finalizar, haré una mención breve a otros sucesos y a un caso del que apenas tengo noticia, los cuales se presentan como relevantes, y que por supuesto, hacen parte de los caminos que se vienen abriendo para estos estudios.

\section{Aportes para la construcción teórica desde una mirada amplia}

Decir que Carlos Jerónimo Atehortúa es uno de los pioneros de los estudios de derecho y cine en Colombia no me parece una afirmación exagerada. En su tesis de grado,

5. Las direcciones de El derecho del cine y de Andrés Botero Bernal son: http://derechodelcine.blogspot.com.co/ y http://www.andresboterobernal.com/ 
publicada en el año 2009, titulada "Aproximación a los estudios de derecho y cine: El cine como medio de aproximación al derecho. Régimen jurídico del cine en Colombia", pone al descubierto senderos interesantes y expone con gran esmero reflexiones que aquí quiero retomar. En su texto, el autor trata el tema bajo un doble enfoque. En la primera parte, llamada "El derecho como objeto de conocimiento del cine", se ocupa del derecho desde lo que el cine puede decirle sobre él, en la segunda parte nombrada "El cine como objeto de regulación jurídica", el cine pasa a ser abordado como materia de ordenación del derecho. En esta ocasión, me dedico a examinar las principales ideas de esa primera parte porque corresponden a la perspectiva desde la cual asumo los estudios.

Atehortúa Arteaga (2009) en su empeño por reclamar que el cine se reconozca como medio adecuado para pensar el derecho, muestra que este último es un objeto de estudio multidisciplinar y que como fenómeno socio-cultural demanda esas otras visiones para enriquecerse; áreas como la antropología jurídica, la sociología jurídica, la filosofía del derecho y el arte, son disciplinas que las encuentra estrechamente relacionadas con lo jurídico. Así, por ejemplo, deja ver que la antropología jurídica estudia el fenómeno de las culturas en relación con el derecho y que la sociología jurídica maneja una visión realista de él. Al igual que ellas, le atribuye al cine una visión externa de lo jurídico.

Además, según el autor, el cine comparte con la sociología jurídica la característica de reclamar una visión de la realidad y también trata temas que se vinculan con la filosofía jurídica. Así las cosas, el cine asume al derecho como un elemento de la sociedad y de la realidad que se ubica en la cultura, presenta sus fenómenos desde una perspectiva original y habría de admitirse que los estudios de derecho y cine contribuyen al estudio no sólo de este campo sino también del social. En su particular referencia hacia la aproximación estética al derecho, Carlos Jerónimo Atehortúa afirma que el arte contiene un discurso sobre él, incluso menciona a las artes plásticas y a la relación entre el derecho y la literatura, ya explorada académicamente; como pasa con ella, dice que el cine permite una aproximación a los problemas del derecho y que es un lenguaje, al igual que el jurídico, susceptible de interpretación.

Considero pertinente citar lo que piensa respecto al cine:

(...) Por otro lado, el cine es arte, representación, lenguaje y fuente de conocimiento que orienta su mirada hacia la totalidad de los objetos del universo. El cine es pensante porque además de la fascinación estética que produce, representa la realidad. El cine constituye un acto de conocimiento, puesto que es una actividad de reflexión acerca del mundo y de los demás individuos. Tanto quien hace cine, como quien acude a él, conoce, interpreta y, como tal, piensa. En consecuencia no podríamos pretender que el arte (y en nuestro caso el cine) ignore una institución de tal entidad como lo es el derecho. (Atehortúa, 2009, p. 32)

Precisamente, uno de los planteamientos que más rescato del autor es el concerniente a las ideas en el cine. Partiendo de que el cine es un medio expresivo complejo, él se basa en Julio Cabrera para explicar que el séptimo arte reproduce las ideas como conceptos-imágenes con un componente emocional, por lo que está dotado de "racionalidad logopática", donde la emoción redefine lo racional (Cabrera, 1999, p. 16 como se citó en Atehortúa, 2009, p. 37). Teniendo presente a Cabrera, explica que: 
(...) Los conceptos-imágenes son los correlatos cinematográficos de aquello que los pensadores no pueden expresar o articular lógicamente para poder ser entendido, teniendo que recurrir a representaciones sensibles, a través de una comprensión 'logopática', o sea sensible y racional al mismo tiempo. (Atehortúa, 2009, p. 37-38)

Para Atehortúa Arteaga, el cine es capaz de modificar la inteligencia sobre el mundo y goza de la facultad de acercar en una nueva dimensión hacia los problemas del pensamiento. Reconoce que su método, como en el derecho, es el argumentativo, y que pertenece al dominio en que participan los valores, apartándose del razonamiento lógico analítico y acudiendo a la retórica de la imagen, mas no de las palabras. En cuanto a su relación directa con el derecho, afirma que existe una tradición jurídica en los argumentos del cine que se ocupa primordialmente de los valores jurídicos y las instituciones. El concepto que maneja el cine sobre el derecho no es pacífico, es decir, encierra muchísimos puntos de vista que son capaces desde reafirmar hasta de criticar lo jurídico.

Siguiendo al autor, el cine al ocuparse de lo jurídico se centra en el derecho que se aplica y no en lo que está por escrito, y dependerá de la posición y agudeza de quien vea una película, el tono jurídico que se pueda hallar en ella. En ese sentido, defiende la idea de que quien lleva a cabo la labor de interpretación jurídica del cine es un artista, por lo que las manifestaciones de quien dirige un filme es apenas una pequeña luz en la búsqueda de su sentido. Para esto, es necesario estar dispuesto a hacer una lectura hacia esa dirección para que sea útil al derecho, en la que se resta el componente de crítica cinematográfica o análisis formal de la película, efectuando una crítica jurídica que supone una posición de este carácter y también política.

En palabras suyas:

(...) El valor que puede tener el cine frente al derecho radica en su capacidad de poner en cuestión las raíces e instituciones mismas de lo jurídico, a través de herramientas y métodos de los que otras disciplinas del conocimiento no disponen. Al ser una actividad que amalgama lo emocional y lo cognitivo, el cine amplía definitivamente el espectro de la reflexión jurídica, llevándola a niveles que otras formas de acercarse al derecho no podrían alcanzar. (Atehortúa, 2009, p. 63)

Entre las conclusiones que él señala, enuncia que el tono científico no es la única vía para aproximarse al derecho, al cual se le pueden aplicar métodos de interpretación que pertenecen al pensamiento estético. Igualmente, expresa que el cine y el derecho son construcciones discursivas que interpretan la realidad e influyen en las fuerzas de la sociedad, son lenguajes que aportan a la construcción social de esa realidad, la cual por sí sola no es suficiente para ser entendida en su dimensión humana, siendo relevante su creación plástica. El derecho así estudiado, bajo la óptica estética, presta un sustrato ético que aporta al desarrollo de la profesión de abogado.

\section{Aportes para la construcción teórica en la pedagogía jurídica}

Continúo ahora con César Oliveros Aya $(2008,2010)$, quien a diferencia de la propuesta amplia de Carlos Jerónimo Atehortúa, dirige sus planteamientos hacia la relación entre el derecho y el cine en el plano pedagógico bajo una postura crítica. Este autor parte de las ideas de Edgar Morin y de Paulo Freire para fundamentar sus reflexiones. En cuanto al primero, se basa en su concepción de la complejidad, según la cual no hay que tomar el conocimiento como compartimentos estancos en 
tanto se eliminarían elementos que hacen parte del tejido del mundo fenoménico, y en cuanto al segundo, toma su idea de visión totalizada por la importancia para su propia comprensión, antes de asumir la totalidad por pedazos.

En esa línea, el abogado y profesor Aya (2010) afirma en uno de sus textos que los nuevos enfoques pedagógicos se fundan en la teoría del pensamiento complejo y que es necesario que el conocimiento se relacione con la realidad. Llama la atención sobre la necesidad de contar con un componente didáctico para la enseñanza jurídica frente al carácter magistral que han adquirido las clases, reconceptualizando el rol mismo del docente, con el fin de generar competencias de índole interpretativo, argumentativo y propositivo, para lo cual el cine es una fuente indicada. Esto se convierte en una ayuda a la metodología tradicional que no cambia radicalmente sino que más bien se ve mejorada.

Además de esto, Oliveros Aya presenta argumentos que se inclinan, por un lado, hacia el nexo entre las nuevas tendencias de los medios virtuales de enseñanza y la docencia jurídica, y por el otro, en la importancia del arte en la educación, por lo que se apoya en la teoría de la educación estética, según la cual lo artístico aporta para la formación integral del ser humano. Su propuesta tiene el rasgo particular de enlazar el cine con el derecho constitucional a través del cine político, por lo que parte de la relación entre el derecho y la política y explica que el derecho constitucional tiene que ver con el poder y la sociedad.

Siguiendo esto, identifica en el cine político una relación con la vulneración o desconocimiento de los derechos humanos y la complementación a la historiografía de lo jurídico. Reconoce en los cineastas políticos un papel activo y hace ver los aportes del cine en momentos destacados de la historia, teniendo en cuenta que existen películas variadas para temas de derecho. Adicionalmente, este autor recurre a la psicología de la percepción y a la mimesis y las relaciona con el cine. En cuanto a la primera afirma lo siguiente:

Siguiendo la corriente de pensamiento de André Bazin, Jean Mitry aparece también como teórico y estudioso del cine como mecanismo para vivenciar la realidad desde una perspectiva psicológica (...) Esa forma de entender el cine, como "moldeador del espíritu humano", a pesar de sonar ambiciosa, conlleva un criterio de verdad en cuanto al apreciar una obra fílmica, con toda la ritualidad que ello implica (penumbra, proyección, espacio adecuado -sala de cine, auditorio-), es una experiencia personal, individual, solitaria, en la que se enfrentan -sería más preciso decir, confrontan- el sujeto y la imagen, siendo ésta un medio de retroalimentación del conocimiento de aquél, cuya incidencia e impresionabilidad varían de acuerdo con variables como el estado de ánimo, el nivel de distractores, el sonido, el brillo de la proyección, etc. (Aya, 2008, p. 156-157)

Respecto a la mimesis, indica que sustenta la correspondencia entre el arte y el conocimiento, en este caso, entre cine y derecho, y le atribuye gran valor al decir que se constituye en su trasfondo teórico. Indica que la mimesis se "(...) traduce en la posibilidad que tiene la labor artística de reflejar segmentos, momentos o porciones de la realidad para, curiosamente, acercarse a ella desde diversos puntos de vista." (Aya, 2008, p. 157). Finalmente, es relevante anotar que este autor, siguiendo ideas de Saturnino De La Torre, resalta el alcance pedagógico del "cine arte", además, dice que el cine es un lenguaje icónico y un medio masivo de comunicación que debe saberse encauzar. 
Ya para terminar este eje teórico paso a Adriana María Ruíz Gutiérrez (2013), quien enfoca su propuesta también en el ámbito de la educación jurídica ligada a una severa crítica hacia ella. En ese sentido, exige que esta sea un espacio de orientación para los estudiantes, para abrir caminos de esperanza y cambio, para la libertad, la solidaridad y la imaginación. Acoge el anarquismo epistemológico de Paul Feyerabend para darle respaldo a sus ideas y las desarrolla en consonancia con los planteamientos de este, en el marco de una sociedad libre. Esta teoría de Feyerabend aboga por una concepción pluralista del mundo, de manera que otras teorías diferentes a la ciencia puedan también explicar el entorno y sea la libertad de pensamiento, y no una ideología totalizante, la que otorgue la oportunidad de imaginar otras formas de vida.

En concordancia con esto, Ruíz Gutiérrez llega a ser más concreta con su contexto y afirma:

La imaginación nos permite aquí desplazar otras teorías y categorías capaces de responder a los problemas de nuestro tiempo: la historia de Occidente y, en particular, la historia de Colombia, nos implica justamente la más alta creatividad y agudeza para recrear otras reflexiones que se distingan de las meras explicaciones causales de los acontecimientos. En materia de educación jurídica, la responsabilidad es, pues, mayor a la simple actualización de los currículos. Cada vez se hace más necesario sustituirlos [sic] métodos abstractos con pretensión de universalidad e imparcialidad por métodos más abiertos que intenten comprender y actualizar las categorías del derecho a partir del diálogo con el cine, la poesía, la política, la historia, la literatura. (Ruíz, 2013, p. 171)

En concordancia con esto, su propuesta de enseñanza e investigación se plantea sobre la pregunta "¿Cómo se enseña y defiende la condición y la finalidad humana desde la Universidad, especialmente desde las Facultades de Derecho?" (Ruíz, 2013, p. 166), pues en su especial preocupación por los estudiantes quiere que ellos no caigan en el olvido de sí ni de los otros, que se conviertan en instrumentos dóciles de saberes que no entienden la realidad o que su comprensión se vierta en la placidez de lo que está dado. Es aquí donde, siendo coherente en sus reflexiones, la autora concibe el cine como una propuesta desde la epistemología anarquista y los currículos alternos, lo concibe como un excelente medio para comprender la relación entre las realidades sociales actuales y el derecho, siendo capaz de poner al descubierto lo oculto.

Así mismo, le atribuye al cine la capacidad de poner al espectador a vivir en el otro y verse en él, yendo más allá, dice que está la posibilidad de lograr una "comunidad emocional" y de resignificar la vida. Encuentra importante para la educación el hecho de que el cine consigue afectaciones para la acción y la transformación. Al partir de esa necesidad de renovación del saber jurídico, es consciente de que requiere de una labor desde las mismas aulas, con los discentes, que tienen en sí mismos el potencial para plantearse cosas diferentes, por lo que exige nuevas mentalidades universitarias que lleven a otras direcciones en el pensar y la transformación política.

\section{Aportes para la práctica en la pedagogía jurídica}

Pasando a lo práctico, a pesar de que no tengo conocimiento de la existencia de redes o páginas especializadas de algún gran proyecto a nivel nacional, tal y como expliqué que está ocurriendo en otras partes del mundo, por supuesto debo iniciar haciendo mención al conocimiento que tengo acerca de la existencia de la Red Iberoamericana de Cine y Derecho, la cual tiene una especial preocupación por el cine 
latinoamericano y que destaco aquí porque, a partir de su vocación panamericana, involucra a algunos personajes que trabajan en el ámbito de estos estudios en nuestro país (Rivaya, 2016, p. 39). Y así como estos y los autores ya mencionados en el eje teórico son relevantes para nuestra trayectoria en los estudios de derecho y cine, las experiencias y consideraciones de quienes se centran en lo práctico de la pedagogía jurídica no dejan de serlo. Empezaré entonces con César Oliveros Aya y luego pasaré a tratar conjuntamente a Adriana María Ruíz y a Luis Alfonso Fajardo.

En el material por medio del cual he estudiado a César Oliveros, me he encontrado con que brinda unas pautas generales para introducir el cine como recurso didáctico en la enseñanza del derecho, para lo cual parte de lineamientos cineclubistas que combina con la formación académica. Advierte que el docente debe revisar preliminarmente el contexto sustancial y formal de la obra con que se vaya a trabajar y propone seguir los siguientes pasos: manejar una información preliminar basada en la ficha técnica del filme y en lecturas complementarias para la preparación de la cinta; efectuar una ponderación temática, a cargo del profesor, en la que identifique los puntos clave de la película que sirvan para el ejercicio académico; presentación y proyección de la obra en un ambiente adecuado, durante la cual el docente debe estar atento a las reacciones de los estudiantes.

Una vez vista la película, César Oliveros propone la realización de un cine foro en el que se socialice el filme y se compartan unas primeras impresiones que permitan ir relacionando el tema de estudio y se moldeen "criterios de verdad". A continuación de esto se pasa a la fijación de saberes, que consiste en la producción académica de los estudiantes, lo cual puede materializarse en un escrito, sustentación oral, entre otras actividades, siendo a su vez la parte evaluativa.

Por otro lado, continuando con Ruíz Gutiérrez y ahora introduciendo a Fajardo Sánchez (s.f.), es pertinente aclarar que en sus textos ambos se identifican como docentes de la Universidad Santo Tomás, ella en la sede de Medellín y él en la sede de Bogotá, en las cuales han contado con experiencias educativas en derecho que han integrado el cine. Me resulta curioso que siendo casos de experiencias reales los autores no entren en detalles de cómo se desarrollan las sesiones, sea de clases o ciclos en los que han vivido su experiencia jurídico-cinematográfica, así que guardan una tendencia menos rigurosa en ese asunto, dándole mayor peso a la relación que construyen entre varios temas jurídicos, que rodean una o más películas, con el mundo del cine en general.

En el caso de Fajardo Sánchez, él explica que las tendencias pedagógicas otorgan importancia a diversas actividades entre las que se encuentra el cine, lo que ayuda a complementar el proceso de enseñanza-aprendizaje y adquirir destrezas, pudiéndose vincular con temas específicos de derecho y manteniendo cautela y perspectiva crítica. Para él, el cine es un fenómeno social que genera estereotipos, racismo y exclusión, siendo objeto de lucha de intereses y confrontaciones ideológicas, religiosas, políticas, morales y éticas, capaz de originar imaginarios, hábitos, entre otros, con repercusión en el ámbito jurídico. Reconoce la existencia de muchas obras cinematográficas que guardan estrecha relación con saberes jurídicos nacionales e internacionales.

Sobre su experiencia práctica concreta, cuenta que la reflexión entre cine y derecho se generó en su institución en la línea de investigación de Derecho y Sociedad, y se incluyó una cátedra de cine y derecho que superó las sesiones de cine-club como 
componente estratégico del área de derechos humanos durante los años 2004 y 2005. Con ella, obtuvieron positivos resultados y los estudiantes escribieron ensayos creativos relacionando las películas con temas de ese ámbito jurídico.

Aunque él no ahonda en explicaciones que den mucha idea sobre las dinámicas seguidas en la cátedra, tomo referencias de un análisis preliminar que realiza sobre la película La sombra del caminante de Ciro Guerra, en su esfuerzo de enlazarlo con el tema de verdad, justicia, reparación y reconciliación en el marco del conflicto armado en Colombia. En su estudio, el autor presenta la película a medida que va desarrollando temas y conceptos propios de los derechos humanos, lo cual me lleva a sospechar que el curso que él comenta muy probablemente ha conllevado reflexiones de este estilo.

Respecto a Adriana María Ruíz, ella cuenta su experiencia práctica en la Facultad de Derecho a partir del cine como un espacio educativo e investigativo. Aunque no brinda información acerca del carácter investigativo de dicho espacio, es muy clara en explicar los ciclos que han llevado a cabo, los cuales son: "Los juristas del horror", para abordar temas del fascismo alemán, "Nuda vida", para tratar la violencia del poder, "Bioética", para examinar la bioética y la biopolítica, "Debido proceso", para estudiar el tema del poder del soberano, "Sentenciado a muerte", "La colonia penitenciaria" y "Desterrados, refugiados y desaparecidos", para abrir paso al tema de la vida.

En los ciclos que ella expone se nota la rigurosidad con que son planeados, porque los conecta en ocasiones con elaboraciones teóricas y conceptos de otros autores que no provienen directamente del mundo del cine sino que tratan estos temas próximos al derecho. Además, brinda justificaciones muy completas y coherentes que explican el sentido de la composición de los ciclos.

\section{Otros caminos en los estudios de derecho y cine}

Antes de concluir tan importante apartado, no puedo dejar de mencionar a María Virginia Gaviria Gil, otra docente, esta vez de la Universidad Eafit en Medellín, quien ya se perfila como una de las personas con gran conocimiento sobre estudios de derecho y cine en Colombia. Ella asume que el cine, y también la literatura, aportan a la resolución de conflictos y a la creación de normas, así mismo, a enriquecer los procesos de aprendizaje y enseñanza del derecho, por lo que reconoce el potencial académico que tienen diversos filmes (Montoya, 2015).

Su proyecto llamado "Relaciones del derecho con la literatura y el cine" se basa en dos enfoques con el fin de convertir la relación de estas disciplinas en un insumo educativo, de manera que se entienda el derecho como un producto humano y se impacten sus procesos educativos, sin alejarse de la cátedra magistral. Entre las actividades contempladas, está su interés por la exploración cinematográfica en cinco continentes, conformar una base de datos cinematográfica e iniciar un curso para estudiantes de maestría en derecho.

De otro lado, tampoco podría ignorar la celebración de un par de eventos universitarios, llevados a cabo en años recientes, y que sin lugar a dudas han sido fuente de inspiración, reflexión y han impulsado la relación entre el derecho y el cine en nuestro contexto. El primero de ellos fue el VIII Seminario Internacional de Teoría General del Derecho denominado Cine y Derecho, celebrado en abril del año 2013 en la Universidad de Medellín. El segundo fue el Seminario Cine y Derecho: En busca de 
otros sentidos, llevado a cabo en septiembre del año 2015 en la Universidad Autónoma Latinoamericana. De este par de acontecimientos surgieron textos que reúnen las respectivas ponencias que se expusieron, resultados que por supuesto también van fortaleciendo el camino de esta unión.

\section{Conclusiones}

El repaso por los orígenes, los desarrollos teóricos, las prácticas y rutas de relación entre el derecho y el cine es alentador y demuestra que, aunque estos estudios son relativamente recientes, hay países en los que ya han tomado una gran fuerza y se han normalizado en los planes de estudio. Los casos de Estados Unidos y España son muestra de que este vínculo no es una ilusión, sino que se ha podido llevar a muy buenos niveles de reflexión, así como a proyectos prácticos, siendo la educación en derecho uno de sus principales objetivos. Entendiendo que las experiencias de contextos lejanos no han sido necesarias para que se inicie una exploración del asunto de forma original, esto fortalece mis motivos para creer que esta historia que apenas empieza en Colombia no tiene ninguna dificultad para ser pensada desde nuestros propios espacios y verse enriquecida por aportes en principio ajenos.

De acuerdo con lo estudiado, es posible concluir que por más distantes que pudieran ser los autores, se identifican con patrones comunes de análisis para el ámbito pedagógico. Coinciden en un desprendimiento, aunque no negación, de las clases magistrales, sea porque necesitan apoyo, son insuficientes o a veces hasta aburridas, oportunidad que se abre para que el cine entre como un recurso apropiado en los cursos de derecho. Así mismo, se nota una ruptura con el formalismo jurídico, con las formas tradicionales de adoptarlo y entenderlo, lo que da lugar a perspectivas críticas que apoyan la introducción del séptimo arte al aula. Aparte de esto, la superación de una lógica científica y racional, la cercanía con la realidad y la emoción, son aspectos constantes en la literatura de derecho y cine, donde tienden a no descuidar la mirada jurídica, siendo la que debe primar al encarar un filme.

Las orientaciones sobre aspectos prácticos o las experiencias compartidas también incurren en similitudes, que ponen la figura del profesor como quien ha de liderar un proceso de suma importancia, señalando fases previas y posteriores que rodean el ejercicio cinematográfico. Sin embargo, la denuncia escéptica de Valentín Thury sobre la manera en que ha observado en la práctica la relación entre derecho y cine, y la mirada amplia y teórica que ofrece Carlos Jerónimo Atehortúa, que lo distingue de la preocupación pedagógica de los demás, son muestras de elementos particulares que van destapando enfoques y posturas que se apartan de los rasgos semejantes de profesores de derecho que estudian el tema.

Finalmente, a partir del conocimiento que tengo sobre Colombia hasta el momento, el hecho de que es a comienzos de este siglo que se empiezan a explorar las posibilidades entre el cine y el derecho, permite comprender que las personas que están en medio de una ubicación dispersa, y que cuentan con fuentes teóricas dispares, son las precursoras en este proceso que se empieza a hacer visible, recorriendo rumbos optimistas que abonan y convocan un futuro atrayente para los estudios de derecho y cine.

\section{Referencias}

Abel Souto, M. (2011). "Desde la literatura, ópera, cine y televisión hasta las ciencias jurídicas y el derecho penal mediante la nueva técnica pedagógica del apren- 
dizaje basado en problemas" [Versión electrónica]. Dereito. 20 (2), pp. 183-205. Recuperado de: http://www.usc.es/revistas/index.php/dereito/article/viewFile/134/63

Agudelo Ramírez, M. (2015). Cine y derechos humanos: una aventura fílmica. Medellín, Ediciones UNAULA.

Agudelo Ramírez, M. (2016). Cine y conflicto armado en Colombia. Medellín, Ediciones UNAULA.

Atehortúa, C. J. (2009). Aproximación a los estudios de derecho y cine: El cine como medio de aproximación al derecho. Régimen jurídico del cine en Colombia. Bogotá, Universidad Externado de Colombia.

Cano Galán, Y. (s.f.) Derecho y cine: implementación y diseño de una estrategia docente en el marco del espacio europeo de educación superior. Recuperado en diciembre 26, 2012, de Redined. Versión digital disponible en: http://redined. mecd.gob.es/xmlui/bitstream/handle/11162/44354/01520113000428.pdf?sequence $=1$ \&isAllowed $=y$

Cobacho López, Á. (2012). <<El empleo del cine en la docencia del Derecho Constitucional>>, en S. García Vázquez (coord.), El derecho constitucional en el cine. Materiales didácticos para un sistema ECTS. 21-28. A Coruña, Universidade da Coruña. Versión digital disponible en: https://presnolinera.files.wordpress. com/2014/01/el-derecho-constitucional-en-el-cine.pdf

Fajardo Sánchez, L. A. (s.f.). "La sombra del caminante: El cine como herramienta pedagógica y didáctica en la enseñanza del derecho" [Versión electrónica]. Revista Virtual Via Inveniendi Et ludicandi: "Camino del hallazgo y del juicio". Recuperado de: http://numanterioresviei.usta.edu.co/articulos/edib/ARTICULOS/ la-sombra-del-caminante.pdf

Montoya, J. (2015). "El derecho a través del cine y los libros", Revista Universidad EAFIT: Periodismo científico, 50 (165), pp. 104-107. Versión digital disponible en: http://www.eafit.edu.co/investigacion/revistacientifica/edicion-165/Paginas/ el-derecho-a-traves-del-cine-y-los-libros.aspx

Oliveros Aya, C. (2008). "El cine como instrumento de enseñanza jurídica" [Versión electrónica]. Cuadernos de la maestría en docencia e investigación universitaria, 1 , pp. 155-162. Versión digital disponible en: http://190.85.246.40/docencia/cuadernosMaestria.pdf

Oliveros Aya, C. (2010). "El cine político: un recurso didáctico en la enseñanza del Derecho Constitucional", Revista Diálogos de Saberes, (33), pp. 245-260. Versión digital disponible en: http://www.unilibre.edu.co/dialogos/admin/upload/uploads/Articulo\%2013.pdf

Pérez Triviño, J. L. (2007), "Cine y Derecho. Aplicaciones docentes" [Versión electrónica]. Quaderns de Cine. (1), pp. 69-78. Recuperado de: http://rua.ua.es/dspace/ bitstream/10045/11378/1/Quaderns Cine N1 08.pdf. 
Rivaya García, B. (2005-2006). "Derecho y cine todo lo que siempre quiso saber sobre el derecho y nunca se atrevió a preguntar", Ratio Juris, (3), pp. 135-151. Versión digital disponible en: http://www.unaula.edu.co/sites/default/files/ratio3.pdf

Rivaya García, B. (2006). <<Derecho y cine: Sobre las posibilidades del cine como instrumento para la didáctica jurídicas>, en M. A. Presno Linera y B. Rivaya, Una introducción cinematográfica al derecho. Valencia, Tirant lo Blanch.

Rivaya García, B. (2010). "Algunas preguntas sobre Derecho y Cine" [Versión electrónica]. Anuario de filosofía del derecho. (26), pp. 219-230. Recuperado de: https:// dialnet.unirioja.es/servlet/articulo?codigo $=3313265$

Rivaya García, B. (2016). "Derecho y cine. A propósito del crimen de lesa cinematografía" [Versión electrónica]. Ética y Cine Journal, 6 (1), pp. 33-39. Recuperado de: http://journal.eticaycine.org/IMG/pdf/JEyC Marzo 201605 Rivaya DerechoyCine.pdf

Rivaya García, B. (s.f.) El cine de los derechos humanos. Recuperado en junio 23, 2012, de la Universidad de Oviedo. Versión digital disponible en: http://www.unioviedo.es/constitucional/docen/derecho/ddff/CINE\%20Y\%20DERECHOS\%2OHUMANOS.pdf

Ruíz Gutiérrez, A. M. (2013). "Imago: el cine en la educación e investigación jurídica", Iustitia, (11), pp. 163-190. Versión digital disponible en: http://revistas.ustabuca. edu.co/index.php/IUSTITIA/article/viewFile/867/670

Salazar Benítez, O. (2015). "La enseñanza del Derecho Constitucional a través del cine" [Versión electrónica]. International Journal of Educational Research and Innovation. (4). Recuperado de: https://www.upo.es/revistas/index.php/IJERI/article/view/1457/1172

Saldarriaga Montoya, J. F. (2013). Ciencia política y cine: Un modelo para armar. Medellín, Ediciones UNAULA.

Thury Cornejo, V. (2009). "El cine, ¿nos aporta algo diferente para la enseñanza del Derecho?" [Versión electrónica]. Academia. Revista sobre enseñanza del Derecho, (14), pp. 59-81. Versión digital disponible en: http://www.derecho.uba.ar/publicaciones/rev_academia/revistas/14/el-cine-nos-aporta-algo-diferente-parala-ensenanza-del-derecho.pdf

\section{Páginas web}

Amnistía Internacional - Cataluña: http://www.amnistiacatalunya.org/edu/pelis/

Andrés Botero Bernal:http://www.andresboterobernal.com/

Cine \& Derecho: https://cineyderecho.wordpress.com/

Derecho al cine: http://www.uco.es/derechoalcine/

El derecho del cine: http://derechodelcine.blogspot.com.co/

Enfoque Derecho: http://enfoquederecho.com/ 
Películas de abogados: http://peliculasdeabogados.blogspot.com/

Proyecto DeCine: https://proyectodecine.wordpress.com/

Thēmis. Acerca de Thēmis, s.f. Disponible en: http://themis.pe/acerca-de-themis-2/

Derecho al cine. La Ciudadanía en Rodaje, s.f. Disponible en: http://dac.edicionendigital.com/ 